\title{
The Sociological Research on Square Dancing in China
}

\author{
Jing Gao \\ School of Physical Education \\ Changzhou University \\ Changzhou, China
}

\begin{abstract}
The popularity of square dancing in the cities of China is generated by many factors and results in many social problems such as, environmental noise, the city appearance and environmental sanitation, the competitive and exclusive ownership of public spaces. Definitely, there exist contradictory versions on square dancing, which might be sociological originated from culture conflict in the period of social transformation in China. The possible revolution for city administration to the problem of square dancing are, respecting the individual right to enjoy public space, constructing public space with humanistic feelings, increasing the ability and experience on social management and governance.
\end{abstract}

Keywords-Square dancing; Public space; Society Introduction

\section{INTRODUCTION}

Square culture is one form of leisure for citizen to perform recreational and sports activities on the public square, which is well recognized and recommended for its grass-roots, openness, large scale .It has been a signal of whether the urban culture is prosperous or not. However, with the development of typical square culture-square dancing in china, the social contradiction between dancing participation and local residents for loud environmental noises emerges up day after day.

\section{THE SOCIOLOGY ANALYSIS TOWARD THE ORIGIN OF SQUARE DANCING}

\section{A. The Need for Social Life}

The related research has manifested that: the typical social state for most of square dancing participant: retired workers and housewives, aged about fifty years old, with monthly income of 1000-2000 RMB, with the junior middle school education or below... Obviously, they belong to the group of people with the character of "middle life crisis" that was proposed by modern social psychology. Most of this kind of people are not self-confident and luck of personality and physical strength and spirit, as well as body shape and appearance degrades day after day. Their professional pursuits is nearly diminished and family structure changed dramatically for their kids got married and settled down

Fund Projects of Chinese Jiangsu Provincial Bureau of Sports (No. ST13300229) elsewhere; their husbands are still active in their careers .At the same time, the tedious routine works to look after their old parents and young grandsons as well as the feeling of uncertainty for their future lives induced their sense of crisis that needed to be expressed. Furthermore, the human's social attribute also requires an urgent need to communicate and interact with others for these type of people. However, the rapid development of urban scale and responding moving residence does not supply good channel of communication for them. With the presence of square dancing, these women in middle-life crisis discover new lands. The noisy excitement of pop music scene and perfect alignment greatly relieve the pressure of their deep crisis feeling, discontent, degradation of the body, emotion assignment. Therefore, square dancing is very popular in middle aged women.

\section{B. Time Brand Mark}

The golden era of the aunts who enjoy the square dancing is the period of "red culture revolution". During that time, collectivism was advocated on a grand scale and individualism was believed to be dangerous. If one person thinks problems or read alone in the room, he or she would be regard as the person with independent thoughts and be dangerous under that atmosphere. Engaging in collective organization, taking part in group event, saying loudly the same slogan, singing the same model songs, the person was regard as reliable and safe person. Otherwise, he would be isolated or criticized. So, the person who experienced the "red culture revolution" often generate a deeply - rooted fear for isolation from organization and strong dependence on organization. By joining the organization, the person can develop sense of belonging, and then the feeling of individual safety.

\section{National Culture Style}

In traditional Chinese practices and customs, everyone is afraid of being desolated and like watching the fun, pay attention to interpersonal relationship. So, only by join community, the man can develop the enhanced sense of belonging, safety feeling and self-recognized feeling. In ancient time, the most of outdoor activity for Chinese people happens in market, street and temple fair. Nowadays, in the process of modernization of Chinese cities, the country began construction of all kinds of characteristics of the square. The city administration promote construction 
residential apartment in large scale as well as construction public space for recreation. This is not simply imitate the western culture, but also relate to the construction of public cultural field. The Chinese public space is different from the free public space in other country in china.

The square is endowed with unique characteristics, local or historic culture. In this context, the square dance is not only in conformity with the Chinese collectivism spirit, but also meet the need of social interaction for current Chinese people.

\section{The Merit of Square Dancing}

Square dancing has the advantages to improve fitness, heart healthy, and brain healthy. Often exercising the square dance, one can improve heart and lung function, accelerate the process of metabolism, and promote digestion, anti-aging, thereby, to improve personal healthy; enhance physical fitness, improve the fitness function of human athletic ability. During performing square dancing, people focus on the appreciation of beautiful music and melody, with rhythm will be emotional expression in dance. By this focus transferring, other body organs, muscles in the body get enough rest and adjustment. Therefore, doing square dancing is helpful to remove people tense mood, relieve mental pressure, remove fatigue, cultivate the soul, feel the happy mood, so as to achieve the best psychological state. During performing square dancing, we not only have to use concept memory, image memory, but also sport memory and emotion memory. Along with the growth of the age, people's memories will gradually decrease, while the jumping square dance have a sustained stimulation of the brain, which can slow down the people memory loss, improve the fitness of brain. Square dance practice is accompanied by the beautiful sounds of music, putting his personal emotions into the dance, making the dance art portraits showing various static and dynamic posture, to shape a variety of beautiful artistic conception combination, embodying beauty shape, beautiful gesture, the creation of art and sports, force and strength combined with the artistic conception, giving people the enjoyment of beauty and art. Therefore, often jump square dance can improve our physique, improve the coordination ability, strong muscles, increase bone density, is a very effective fitness practice.

\section{SOCIOLOGICAL ORIGIN OF THE PRODUCTION OF CONTRADICTIONS IN SQUARE DANCING}

\section{A. Sociological Origin of the Production of Contradictions in Square Dancing}

The pure public product at least has the following characteristics: non-competitive and non-exclusive consumption, fully provided by the government. As long as the public service have the above mentioned two points, we can think it is pure public products, such as: national defense, law, diplomacy etc. Quasi-public product means product with some extent exclusiveness and competitiveness, such as education, culture, sports, medical care. The densely populated city, the residents need to share a common space. In theory, the public space of city will be open to all residents, anyone can walk the dog, for a walk, make the game in there. But, if a public space is occupied by a group of people for long time, this means that usage right of the public space has competitiveness and exclusiveness. So, the public square where the middle aged women jump square dancing belongs to quasi-public product. It is needed for them to follow certain rules when they shared the common resource and did collective action. For example, in USA, occupying public venues for group activities need to apply in advance, and the sponsors need to spend some of the costs. That is to say, the public square cannot be solo-occupied by square dancers. In addition, the more and more contradiction between the lack of city public space and the increasing needs of public culture exists. On one hand, we see that the landmark building, cultural arts center going up, on the other hand, the public space has been reduced to be private products with stated price, serving for a few portion of people. Serious lack of public space for lovers of the square dance are difficult to find space to dance. If they jump in residents area, the release of the concert affect the area where residents rest and learn; if they jump in park, it is also difficult to find places for dancing, and the park and residents area always stay near., even there is place in park to jump, there also exist disturbing, so as long as where the square dance is jumping, there is contradictions between the residents and dancers. In addition, just as what pointed out many years ago by Mr. Xiaotong Fei, in china, Many people feel that the public space is belonging to nobody, so the clear public river often change to garbage ditch in southern Yangtze area. Nowadays with the Chinese urbanization process, city population is more and more intensive, square dancer face more and more space competitors, such as vendor or commodity exhibition. The problem of exclusive and competitive right to use the public space is more and more prominent in urban city.

\section{B. Culture conflict in the period of transformation of society in China}

The aunts who are fond of jumping square dance are demonized to some extent as the code of low-appetite, low IQ, this is originated from the culture conflict in the period of transformation of society. From the point of society order view, Nowadays Chinese social transition is transformation from acquaintances society "rules" to the stranger society "rule of law". In his famous book" agrestic China", Dr. Fei said that rule is pivot in traditional agrestic Chinese society. The mainstream of square dancing aunts were born and grew in "red culture revolution", so they have the distinctive characteristics of that times, one is keeping rules, the two is to participate in collective activities. In addition, most of them suffered the middle-life crisis now. As a result, the square dancing is popular among these aunts. It should be noted that most of active square dancing aunt have dual social roles: they are mother in traditional family, they are also the immigrated old, in the Chinese urbanization process they moved from rural life to city life with their children or husband. But for them the city is neither their working space nor their own social interacting space, it is completely new and strange land. What connect her to the city is her children or husband. Square dancing is possibly developed as a 
communicating and social interacting tool by these immigrated old women in new and strange city.

From the era of being disciplined to the age of relative freedom, let aunts face at a loss of freedom. In the ten years of the cultures revolution, the national masses of the people focus on the wave of political movement, thus forming a certain extent, the "philosophy of struggle" consciousness. With the subsequent implement of policy of reform and opening up, the national life is replaced to economy-oriented and economic construction is the baton of society development. People neither have consciousness nor time to cultivate public spirit and construct public space. Nowadays, with the rapid development of china economy, city hardware is developed more and more, constructed the Plaza is increasing, but the people did not cultivate the corresponding "square spirit". Therefore, when different group appeal for their own interest in square, there is conflict. These interestrelated are used to adopt "philosophy of struggle" to fight each other. There is no wall in square, so anyone can enter and depart freely, but in their deep heart there is some constrain who would like to transform square to "battle field". We lack of tradition of live harmony in square, that is, to compromise and share mutely in public space, as a result, the square conflict is developed more and more in many city.

\section{TO SOLVE THE CONTRADICTION OF THE SQUARE DANCING BY THE SOCIOLOGICAL METHOD}

\section{A. Protect and Respect Everyone's Right to Enjoy the Public Space}

No one should blame aunts who jump square dancing to achieve physical fitness and mental pleasure, but it is also recommended that mass enjoying is better than solo enjoying. Anyone who is satisfying his own desire should not do harm to others physical and mental health. The aunts have the right to jump square dancing in square, while the residents affected by the square dancing have the right to keep their life not to be disturbed by square dancing. The aunts and residents should not be the opposite two sides. Since the square is a public living space, we should consider the overall interests firstly, then, balance the interest of the opposite two sides, through consultation, communication mutely. The opposite two side should understand each other, express own opinion, appeal own demand. In order to achieve the purpose of self-education and public education, on one hand, let the massive citizen know the fact that jumping square dancing is the fitness entertainment with the highest profit and the lowest cost, on other hand, let the dancing aunts know the fact that there is negative effect of square dancing such as, loud noise, light pollution. From now, we should learn to protect the public interest, respect the rights of others.

\section{B. Constructing Public Space with Humanistic Feelings}

The development of the society not only take into account people's material needs, but also should pay attention to people's spiritual needs. The building of socialism should be people-oriented, all-round to meet the needs of the people. The construction of public space is closely connected with daily life, and should be regarded as important as living facilities, transportation, and commerce and so on. Both the responsible design, serious construction for government and positive participation, actively maintenances for the citizen are needed. The humanistic feelings should be adopted when government or enterprises construct urban public space. Not only to provide more public space for the citizen, but also give full consideration to the utilizing ratio of these public space. Not only to improve the grade of public space, but also take into account the rationality of these public space. For example, due to improve the grade of the city and meet needs of hosting sports event, construction of large-scale public gymnasiums is often thought as so called face engineering by city administration. However, the address is often too concentrated, resulting in poor population coverage rate, benefit less for the masses; the building design pay attention to meet the demand for hosting big sports event, resulting in waste of space resource and poor utilizing ratio of these building afterwards. Therefore, it is a problem that should not be neglected for city administration, how to further satisfy the needs of citizen in the process of planning the layout of construction and how to accelerate the public facilities and space harmonized with the nature. The construction of public space should follow sustainable development and humanism philosophy, so everyone including dancing aunts can share the interest of public space resource.

\section{Increasing the Ability and Experience on Social Management and Supervision}

In the face of public interest, the freedom of the opposite two sides in square dancing should be restricted. The social administration department should change the situation that Improper regulations, lack of law, vacancy of law enforcement; make the penalty details clear according to relevant laws and regulations; assign the management responsibilities of different administration units; strengthen guidance and management of the mass cultural and recreational activities, pay attention to the law education, help people to improve the consciousness of social morality and civilization, so as to achieve the creation of peace and harmony city living environment. Specifically speaking, the conflict of square dancing belongs to social conflict and square dancing is one of the producer of environmental noises. From the point of law view, EPA has the right and obligation to treat this problem. In addition, the public security authorities and city departments have the responsibility and authority to solve the widely-existing city problem. Aiming at the noise pollution caused by square dancing, the all levels of government departments should formulate and supplement the corresponding laws and regulations. We should emphasis and strengthen the education of law on dancing aunts, improve their social morality-obey the game rule and do not infringe others rights to study, life and rest when they enjoy dancing freely in square. 


\section{CONCLUSION}

In conclusion, with the rapid development of the city, the new contradiction and problems continuously test our social coordination mechanism and governance mechanism. It will be helpful to resolve the interests of the opposite two sides involving square dancing to construct a multi-roles participation of social management pattern and to improve the level and ability of social management and governance.

\section{REFERENCES}

[1] T. T. Guo, The primary research on the fitness merits and development trends of square dancing, Current Sports Technology, vol. 35 , pp. 161-162, 2013.

[2] X Chen, The difficulty of cultivating the citizenship culture, Teaching and Education Form, vol.11, pp. 148-149, 2014.

[3] R. Zhou, The current state of development of citizenship culture and constructing strategies, Bulletin of Jiangning Administration School, vol.7, pp. 138, 2010.

[4] R. Z. Yang, the theory of public field and construction of harmony society, Sociological Literature Express, Beijing, 2013, pp.1.

[5] J. Clerk Maxwell, A Treatise on Electricity and Magnetism, 3rd ed., vol. 2. Oxford: Clarendon, 1892, pp.68-73. 